\title{
The multiple fates of subducted sediments
}

\author{
BENJAMIN Z. KLEIN ${ }^{1, *}$ AND MARK D. BEHN ${ }^{1}$ \\ ${ }^{1}$ Department of Earth and Environmental Sciences, Boston \\ College, Chestnut Hill, MA 02467, USA \\ (*correspondence: benjamin.klein@bc.edu)
}

Subduction of sediments is the dominant process on Earth where material from the Earth's surface is returned to the mantle, modulating trace element recycling, volatile budgets, and potentially the generation of mantle heterogeneities. Despite this significance, the fate of subducted sediments remains uncertain. For example, it is argued that arc lava compositions require the contribution of subducted sediments melts; however, this observation is inconsistent with subduction zone thermal models, which suggest that slabtop sediments likely remain too cold to melt and contribute to subduction zone magmas. This apparent contradiction can be reconciled if sediments first form buoyant diapirs that rise into the mantle wedge, where higher temperatures promote melting.

To evaluate this process, we develop a new coupled thermodynamic-geodynamic model of diapir evolution within the mantle wedge. Specifically, we calculate the equilibrium melt and residual mineral assemblage and buoyancy of diapirs as they advect through and thermally equilibrate with the mantle wedge. With this model, we evaluate the conditions under which diapir formation and ascent is favored, and where melting of these diapirs occurs. Critically, we find that all but the most mafic subducted sediment compositions are buoyant relative to the overlying mantle at slabtop conditions, and are likely to form diapirs given reasonable assumptions about subducted sediment thickness and background strain rates. These buoyant diapirs will transit the mantle wedge, and melting occurs rapidly as the diapir passes into hotter portions of the wedge. Further, our model shows that if melt extraction is inefficient, diapir buoyancy increases during melting, promoting ascent through the mantle wedge and eventual 'relamination' to the base of the overlying arc crust. However, if melt extraction occurs rapidly, all but the most silica-rich sediment compositions yield garnet-rich residues that are denser than the mantle wedge. These residues stagnate during ascent and will be recycled into the mantle. Using this model, we highlight modern arc locations where these disparate sediment fates are likely to occur, and speculate on the importance of diapir residues in the formation of mantle heterogeneities. 